\title{
SYMPTOMS AND LUNG FUNCTION VALUES IN NIGERIAN MEN AND WOMEN EXPOSED TO DUST GENERATED FROM CRUSHING OF GRANITE ROCKS IN CALABAR, NIGERIA.
}

\author{
S. E. UROM; A. B. ANTAI and * E. E. OSIM \\ Department of Physiology, College of Medical Sciences, University of Calabar, Calabar, Nigeria.
}

Summary: This study was carried out to determine lung function and respiratory and non-respiratory symptoms among men and women exposed to dust emitted from crushing of granite rocks and to compare them with control men and women not exposed to any known air pollutant. The sites were the granite rock crushing industries in old Netim, Akamkpa Local Government Area of Cross River State, Nigeria. Respirable dust level was higher in the dust-emitting sites $\left(1.087 \pm 0.243 \mathrm{mg} / \mathrm{m}^{3}\right)$ than in the control areas $\left(0.099 \pm 0.007 \mathrm{mg} / \mathrm{m}^{3} ; p<0.001\right)$. The mean anthropometric parameters (age, body weight and height) between the two groups were not significantly different. However, all the values of lung function indices except $\mathrm{FEV}_{1} \%$ were significantly lower in the dust-exposed group than their control group. ( $p<0.001$ for $F E V_{1}, F V C$ and PEFR) thus, suggesting restrictive lung defect among the exposed workers. Lung function indices correlated negatively with duration of service of the granite industry workers. The incidence of the major respiratory symptoms viz: unproductive cough, chest pain, catarrh and dyspnoea among the test group were higher $(p<0.05-0.001)$ than in control group. Among the presenting non-respiratory symptoms, headache and night sweat were more common in the dust-exposed group than the control subjects $(p<0.001)$. Chronic exposure to dust generated from crushing of granite rocks impairs lung function and causes some respiratory and non-respiratory symptoms in men and women. Length of service was a predisposing risk factor.

Key Words: $\quad$ Lung function, Granite, Dust, Symptoms

\section{Introduction}

Every year, there are 50 million cases of occupational respiratory diseases caused by inhalation of toxic dust and chemicals, which are allergenic and carcinogenic agents. (19) A lot of dust and gases are generated in rock crushing and mining industries. Precautionary measures against inhalation of dust at the rock crushing sites are generally poor or nonexistent owing to lack of resources by the management of the industries and ignorance of the rock crushers. The granite rock crushing companies in Old Netim, Akamkpa, Cross River State of Nigeria generates a lot of dust in its vicinity hence, chronically exposing the workers to the granite dust. Some dusty occupations impair lung function, and cause pneumoconiosis (Osim et al, 1996; Wang et al, 1997; Kampalath et al, 1998). Unfortunately, our knowledge about what dusts and chemicals cause disease and how, is imprecise (Ellenhorn and Barcelloux, 1998). Furthermore, explosives used for rock blasting are emulsion explosives (EMEX) or ammonium nitrate fuel oil (ANFO) mixed with poisonous gases e.g carbon-monoxide, carbon-dioxide, nitrous fumes and ammonia which are reported to damage the respiratory system and impair lung function (Sawa et al, 1981; Douglas et al, 1989; Raphael et al, 1989). There are few reports on the effect of exposure to granite dust in exposed workers in several parts of the world (Ng et al, 1992; Melmberg et al, 1993; Graham et al, 1994; Eisen et al, 1995). There are however, no reports on Africans concerning the effects of granite dust on the health of exposed workers. Respiratory and other associated symptoms other than carcinogenic effects have not been reported. Therefore, the aim of the study was to determine the lung function status as well as respiratory and other associated symptoms of Nigerian men and women chronically exposed to dust generated from the granite rock crushing industries in Old Netim in Akamkpa local government area of Cross River State of Nigeria.

\author{
Materials and Methods \\ Subjects \\ The subjects comprised test and \\ control groups. The test group comprised 344
}


men and 27 women who were exposed to dust generated from crushing of granite rocks in Old Netim, Akamkpa, Cross River State of Nigeria. Their duration of exposure to dust ranged from 4 months ( 0.33 year) to 20 years. Fourteen percent of the males were either cigarette smokers or past smokers while none of the females was a cigarette smoker. The control group comprised of 216 men and 111 women who were not exposed to any known air pollutant. Fifteen percent of the males were either active cigarette smokers or past smokers. None of the control females was a cigarette smoker. The anthropometric parameters, viz; age, height and body weight of the test and control groups were similar. Their smoking habit was also similar. Forced vital capacity (FVC), Forced expiratory volume in one second $\left(\mathrm{FEV}_{1}\right), \mathrm{FEV}_{1}$ as a percentage of FVC $\left(\mathrm{FEV}_{1} \%\right)$ and Peak expiratory flow rate (PEFR) were used to assess lung function. A vitalograph spirometer (Vitalograph Limited, Buckingham, England) was used to measure FVC and $\mathrm{FEV}_{1}$, while $\mathrm{FEV}_{1} \%$ was computed. A mini-Wright peak flow meter (Airmed Clement Clark International Ltd, England) was used to measure PEFR. The dust-exposed workers namely: company workers, tipper drivers, middlemen and villagers were exposed to dust for about 8 hours daily for five days each week since the company operated for 8 hours everyday and five days a week.

\section{Test Procedure}

The subjects were called in groups and instructed to the test procedures after which the procedures were demonstrated to them for better understanding. A questionnaire was completed after which the tests were performed on the subjects individually. The questionnaire recorded; names, smoking habit, and history of respiratory (pulmonary) and non-respiratory diseases, while height without shoes and weight with light clothing were measured and recorded.

\section{Dust Sampling}

The concentration of respirable dust in both test and control sites was measured using a gravimetric dust sampler manufactured by the Department of Physics, University of Calabar, Nigeria. The instrument measured the concentration of respirable dust as it maintains a constant supply of air at a rate of 2 litres per minute through its filter for 4 hours. The Respirable dust was sampled in four control and four test sites and their means were calculated.

\section{Comparisons Performed}

From the forced expiratory spirograms, comparisons between ventilatory function indices (FVC, FEV, $\mathrm{FEV}_{1} \%$ and PEFR) were done for dust exposed subjects and their controls. The incidence (\%) of respiratory and other symptoms in the dust levels in test sites were compared. The mean concentrations of respirable dust levels in test and control sites were also compared.

\section{Statistical Analysis}

The student's unpaired t-test was employed in the comparison of ventilatory function indices and dust levels in the control and test environments. Chi square-test was used to test for significance between percentages Data are presented as mean and standard error of the mean (SEM). A P-value of $<0.05$ was considered as significant.

\section{Results}

The anthropometric parameters and ventilatory functions indices of adult male and females in control sites and those in dusty were compared. There were no statistically significant differences in the mean anthropometric values between the two group. On the other hand, the ventilatory functions indices $\mathrm{FEV}_{1}$, FEC and PEFR in the control group were significantly higher $\left(p^{<0.001)}\right.$ than in the dust-exposed (test) group. However, in both males and females, there was no significant difference $(p>0.05)$ in the value of $\mathrm{FEV}_{1} \%$ between the control and test subjects (Tables 1 and 2). 
Table 1: Comparison of mean values of anthropometric parameters (age, height and weight) and ventilatory function indices (FVC, FEV1, FEV1\% and PEFR) of adult males in control sites with those industries

\begin{tabular}{cccc}
\hline Parameters & Control $(\mathrm{N}=216)$ & Test $(\mathrm{N}=344)$ & $\mathrm{p}$-value \\
\hline Age (yrs) & $33.29 \pm 0.56$ & $32.45 \pm 0.43$ & NS \\
Height (m) & $1.74 \pm 0.01$ & $1.76 \pm 0.04$ & NS \\
Weight (kg) & $67.17 \pm 0.71$ & $67.69 \pm 0.50$ & NS \\
FVC (L) & $3.90 \pm 0.08$ & $3.49 \pm 0.05$ & $* * *$ \\
FEV $_{1}(\mathrm{~L})$ & $3.10 \pm 0.07$ & $2.73 \pm 0.05$ & $* * *$ \\
FEV $_{1} \%$ & $78.25 \pm 0.80$ & $77.34 \pm 0.67$ & NS \\
PEFR (L/min) & $569.36 \pm 5.91$ & $508.71 \pm 4.64$ & $* * *$ \\
\hline
\end{tabular}

NS $=$ Not statistically significant, $* * *=p<0.001$

Table 2: comparison of mean values of anthropometric parameters (age, height and weight) and ventilatory function indices (FVC, FEV1, FEV1\% and PEFR) of adult females in control sites with those industries

\begin{tabular}{cccc}
\hline Parameters & $\begin{array}{c}\text { Control }(\mathrm{N}= \\
111)\end{array}$ & Test $(\mathrm{N}=27)$ & p-value \\
& $28.79 \pm 0.61$ & $27.96 \pm 1.13$ & NS \\
\hline Age (yrs) & $1.65 \pm 0.01$ & $1.67 \pm 0.01$ & NS \\
Height (m) & $65.48 \pm 1.26$ & $64.8 \pm 2.26$ & NS \\
Weight (kg) & $2.70 \pm 0.07$ & $2.18 \pm 0.09$ & $* * *$ \\
FVC (L) & $2.14 \pm 0.06$ & $1.72 \pm 0.09$ & $* * *$ \\
FEV $_{1}(\mathrm{~L})$ & $79.71 \pm 0.99$ & $77.28 \pm 2.79$ & NS \\
FEV $_{1} \%$ & $345.53 \pm 6.68$ & $308.81 \pm 12.37$ & $* * *$ \\
PEFR $(L / m i n)$ & & & \\
\hline
\end{tabular}

NS $=$ Not statistically significant, $* * *=p<0.01$

The duration of service of male subjects in the granite-dust generating industries correlated negatively with lung function indices. $\mathrm{FEV}_{1}$, FVC and PEFR showed a significant negative correlation $(p<0.0)$ with duration of service in males, while $\mathrm{FEV}_{1} \%$ versus length of service was not significant (figures 1, 2 and 3). Among the females, only PEFR showed a significant negative correlation $(\mathrm{p}<0.001)$ with the duration of service (Figure 4).

Comparison of respiratory symptoms observed among the dust-exposed and control groups shows that the incidence of unproductive (dry) cough, chest pain, catarrh and dyspnoea were also significantly higher in the dust-exposed group than in the controls $(\mathrm{p}<0.05-0.001)$. However, the incidence of productive cough and sneezing were similar in the two groups $(\mathrm{P}<0.05)$ (Table 3$)$.

The non-respiratory symptoms studied revealed significantly higher incidences of headache and night-sweat in the dust-exposed group than in their controls $(\mathrm{p}<0.001$, respectively), (Table 4). However, weight loss and fever were not significantly different in the two groups of subjects.

The mean concentration of atmospheric dust level in the vicinity of the granite rock crushing industries was $1.087 \pm 0.242 \mathrm{mg} / \mathrm{m}^{3}$ which was significantly higher than in the control sites $-0.099 \pm 0.007 \mathrm{mg} / \mathrm{m}^{3}(\mathrm{p}<0.001)$.

Table 3: Comparison of respiratory symptoms observed among control and dust exposed subjects

\begin{tabular}{cccc}
\hline $\begin{array}{c}\text { Respiratory } \\
\text { Symptoms }\end{array}$ & $\begin{array}{c}\text { Dust-Exposed Subjects } \\
\text { Incidence in \% } \\
(\mathrm{N}=371)\end{array}$ & $\begin{array}{c}\text { Control Subjects } \\
\text { Incidence in \% } \\
(\mathrm{N}=327)\end{array}$ & $\begin{array}{c}\text { Level of } \\
\text { Significance }\end{array}$ \\
\hline Cough & 7.28 & 3.24 & $* * *$ \\
Dry & 15.09 & 14.98 & $\mathrm{NS}$ \\
Productive & 8.09 & 3.98 & $* * *$ \\
Chest pain & 2.70 & 1.53 & $*$ \\
Dyspnoea & 26.95 & 19.57 & $* *$ \\
Catarrh & 11.52 & 8.21 & $*$ \\
Sneezing & \multicolumn{2}{c}{ Not statistically significant }
\end{tabular}


S. E. Urom et al

Table 4: comparison of respiratory symptoms observed among control and dust exposed subjects

\begin{tabular}{cccc|}
\hline $\begin{array}{c}\text { Respiratory } \\
\text { Symptoms }\end{array}$ & $\begin{array}{c}\text { Dust-Exposed } \\
\text { Subjects } \\
\text { Incidence in \% } \\
(\mathrm{N}=371)\end{array}$ & $\begin{array}{c}\text { Control Subjects } \\
\text { Incidence in \% } \\
(\mathrm{N}=327)\end{array}$ & $\begin{array}{c}\text { Level of } \\
\text { Significance }\end{array}$ \\
\hline Headache & 10.51 & 4.28 & $* * *$ \\
Weight & 1.35 & 0.92 & NS \\
Night sweat & 1.62 & 0.00 & $* * *$ \\
Fever & 5.93 & 5.81 & NS \\
\hline
\end{tabular}

NS $=$ Not statistically significant, $* * * \quad=\mathrm{p}<0.001$

Fig. 1 Correlation between duration of service and $\mathrm{FEV}_{1}$ (Test-males)

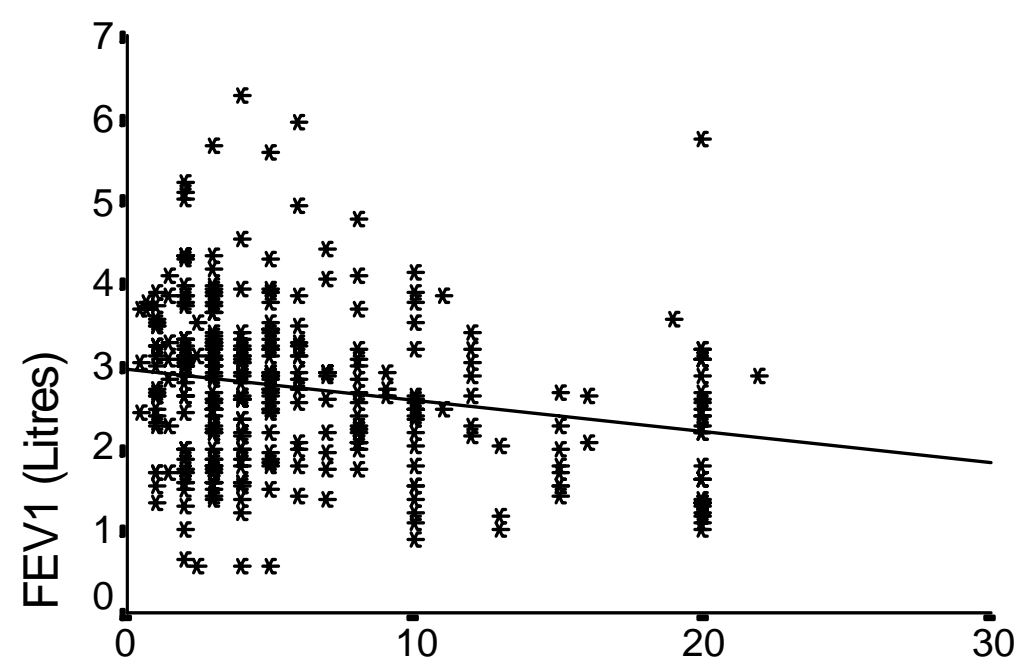

Duration of service (years) males exposed to granite dust

FIG. 2 Correlation between duration of service and FVC $(L)$ of males exposed to granite dust

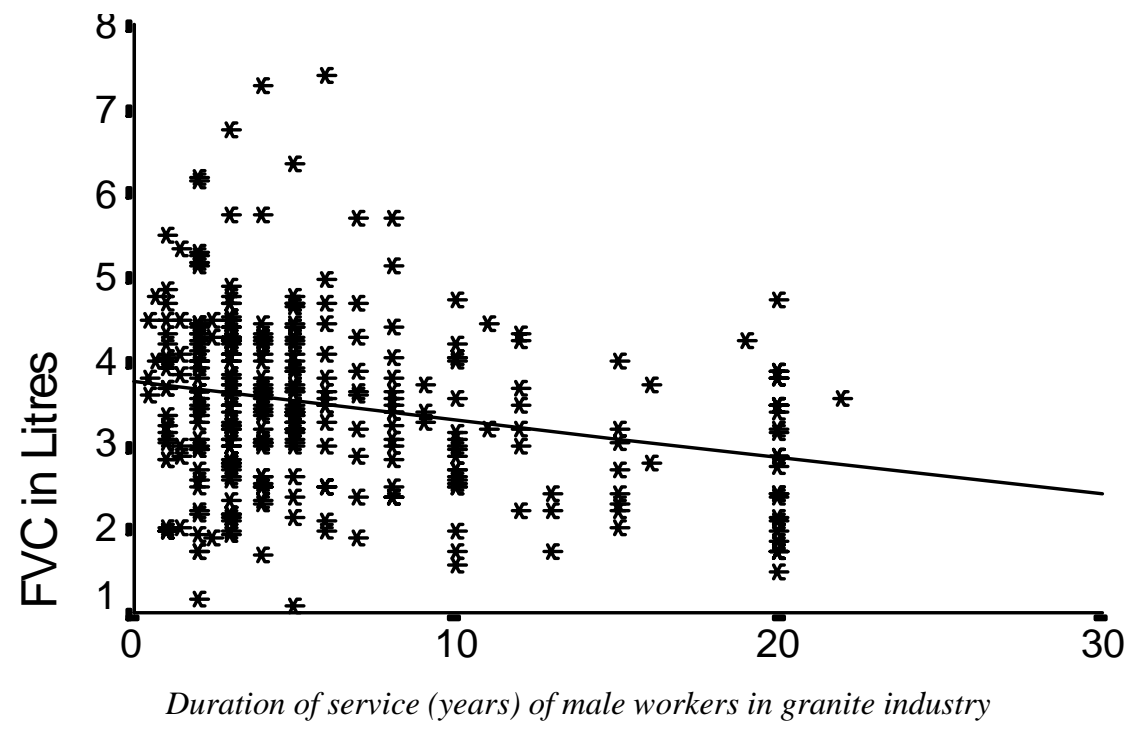


Symptoms and lung function in granite dust-exposed workers

FIG. 3 Correlation between duration of service and PEFR (L/min) of males exposed to granite dust

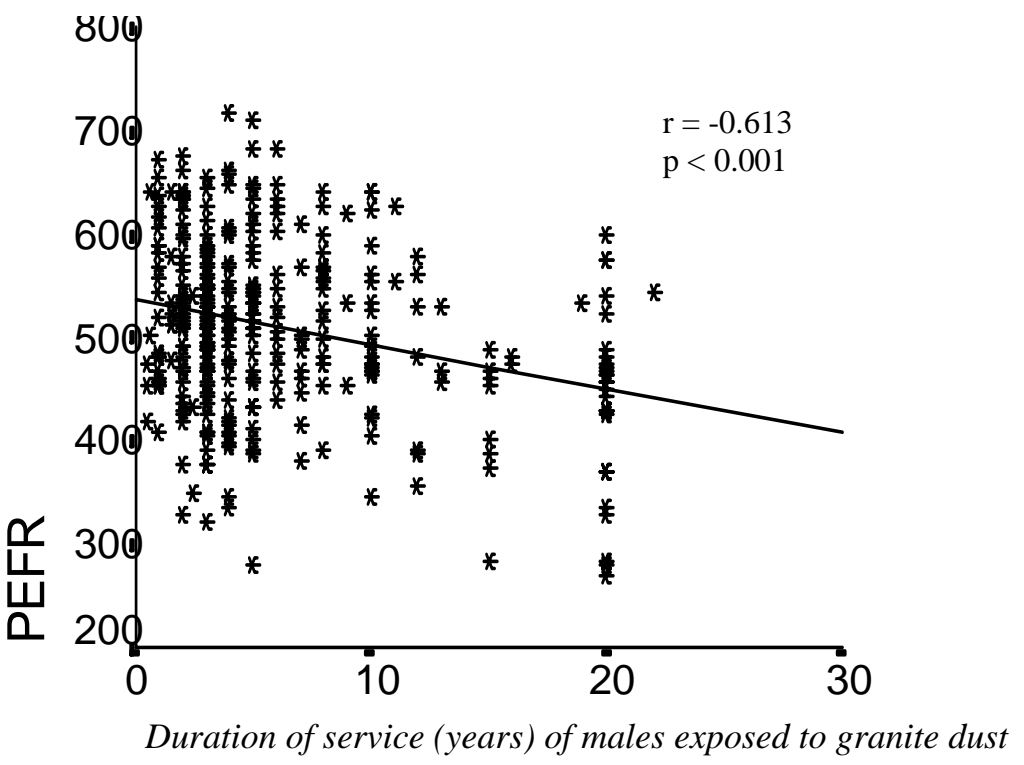

FIG. 4 Correlation between duration of service and PEFR $(\mathrm{L} / \mathrm{min})$ of females exposed to granite dust

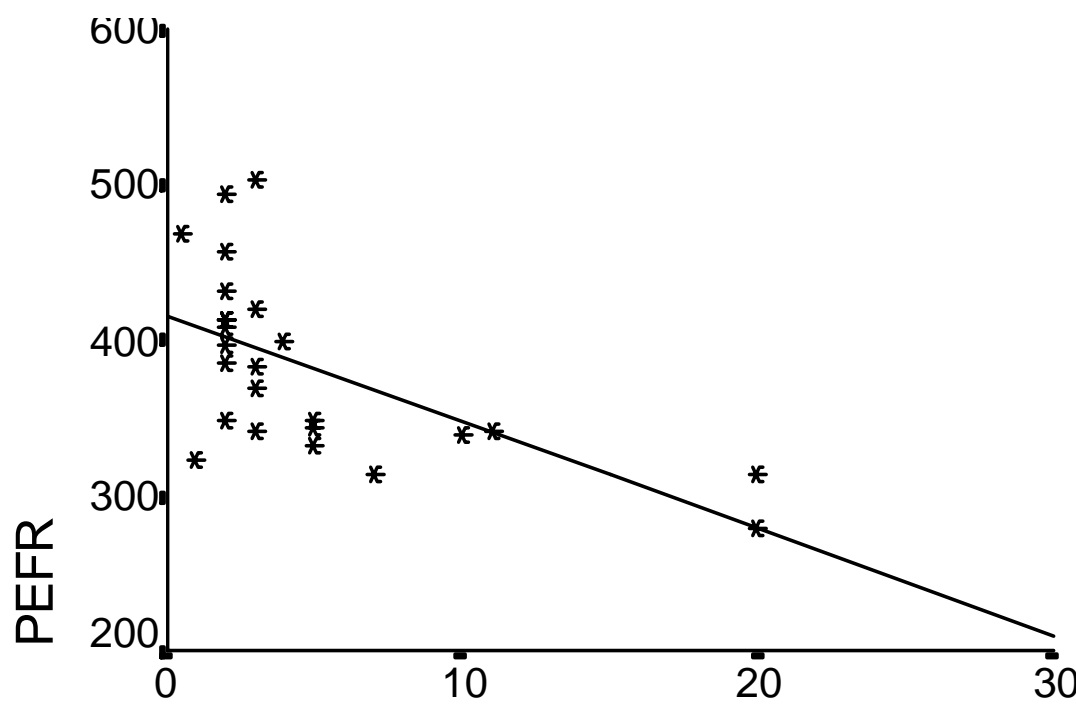

Duration of service (years) of females exposed to granite dust 
Discussion

The mean values of ventilatory function indices for the control group obtained in this study were similar to values reported for apparently healthy adult male and female Nigerians (Osim and Esin, 1996). Several investigators have shown that anthropometric parameter have significant relationship with lung function indices (Johnson and Erasmus, 1968; Aderele and Oduwole, 1983; Jaja and Fagbenro 1995). Therefore, it was necessary to ensure that the anthropometric parameters of the two groups (control and test) were similar as was done in this study.

The results obtained in this study showed that mean values of FVC, $\mathrm{FEV}_{1}$ and PEFR of men and women in the granite industry were significantly lower than the values of those in control sites. $\mathrm{FEV}_{1} \%$ was however, not significantly different. These deviations are characteristics of restrictive lung defect (West, 1979). So the subjects living or working in the vicinity of the dust-emitting granite rockcrushing industry in Old Netim in Akamkpa LGA of Cross River State of Nigeria generally showed a restrictive lung function impairment.

Although our results show a significant lowering of lung function values in the dustexposed subjects compared to their control group, it was not possible to determine all the factors that may be responsible for lung function impairment in the dust-exposed subjects. However, dust sampling in both dusty and control environments suggests that chronic exposure to granite dust may be a factor since the respirable dust level in the dusty environment was very high when compared to the control environment. Granite rocks contain quartz (silica), plagioclase and feldspar (Ekwueme, 1993). Although the relatively high dust level might be a factor, there may be other confounding causative factors. Poisonous gases such as carbon monoxide, carbon dioxide, nitrous fumes and ammonia are emitted from the explosives used in rock blasting which reportedly damage the respiratory system and impair lung function (Raphael et al, 1989; Kocks and Scot 1990 and Harre et al, 1997). It is therefore possible that poisonous gases contributed to the impairment of lung function of subjects in the dusty environment. Unfortunately, environmental gas levels were measured owing to technical problems.

Correlation tests also showed that the lung function of dust-exposed male and female workers in the industry decreased significantly with increased length of their service. The worsening of lung function with length of service is indicative of the importance of the duration of exposure as one of the major resdisposing factors in the aetiology of lung function impairment among the granite-dust exposed male and female workers studied. The major presenting respiratory symptoms were unproductive cough, chest pain, catarrh and dyspnoea, and these were significantly higher in the dust-exposed subjects than in their controls. As stated earlier, respirable dust level in the vicinities of the granite rock crushing industries was higher than in control sites. Silica in the dust is allergenic and may therefore irritate the respiratory tact leading to unproductive cough and other respiratory symptoms (Ellenhorn and Barcelloux, 1998). Although the results showed significant lowering of lung function values in the dustexposed subjects when compared to their control, the reduction (10-15\%) was not large. The efficiency of the dust-exposed workers was not yet compromised. However, correlation test of duration of service and lung function indices showed that with time lung function impairment will be worse and could be fatal. As there was no radiographic examination, it is not possible to know if pneumoconiosis had set in the dust-exposed workers. Lung function tests are a means of early detection of lung functional impairment even without radiographic signs of the disease (Wright et al, 1988). So frequent lung function testing in vicinity of granite rock blasting industry should be enforced and precautionary measures should be introduced in the industry studied. Workers severely affected should be redeployed to other less hazardous areas.

In conclusion, chronic exposure to dust from crushing of granite rock can impair lung function and causes respiratory and other symptoms. Length of exposure is a predisposing risk factor.

\section{References}

Aderele, W.I. and Oduwole, O. (1983) Peak expiratory flow rate in healthy school children. Nig. J. Paed. 10: 45-55.

Begin, R., Lesur, O., Bouhadiba, T., Goujian, L., Larivee, P., Melloni, B., Martel, M. and Cantin, A. (1993). Phospholilipid content of bronchiolar lavage fluid in granite workers with silicosis in Quebec. Thorax 48: 840 - 844 .

Douglas, W. W., Hepper, N. H. G and Cosby, T. V., (1989) Silo-filter's Disease. Mayo Clinical Proceedings 4: 281 - 304.

Eisen E. A., Wegmen, D. H., Louis, T. A., Smith, T. G. and Peter, J. M. (1995) Health worker effect in a longitudinal 
study of one-second forced expiratory volume $\left(\mathrm{FEV}_{1}\right)$ and chronic exposure to granite dust. Int. J. Epidemiology 24(6): 1154 - 1161.

Ekwueme, B. N. (1993) An easy approach to igneous petrology $\left(1^{\text {st }}\right.$ ed.) pp 29-30; 9798.

Ellenhorn M. J., Barceloux, D. G. (1998) Toxicology: Diagnosis and Treatment of Human Poisoning. New York. Elsevier, 53-171.

Graham, W. G., Weaver S., Ashikaja, T., O’Grady R. V. (1994) Longitudinal pulmonary function losses in Vermont granite workers: A re-evaluation. Chest 106 (1): $125-130$.

Harre, E.S.; Price, P. D, Ayrey, R. B., Toop, L. J., Marting, R. and Town, G. I. (1997). Respiratory effects of air pollution in chronic obstructive pulmonary disease; a three month prospective study. Thorax 52 (12): 1040 - 1044.

Jaja, S. I. and Fagbenro, A. O. (1995) Expiratory flow rate in Nigerians school children. African Journal Med. Med. Science. 24: 379-384.

Johnson, Z.M. and Erasmus, L. D. (1968). Clinical spirometry in normal Bantu children. Am. Review of Resp. Dis. 97: 585 -590 .

Kampalath, B. N, McMahon, J. T., Cohen, A., Tomashifski, J. K. and Kleinerman, J. (1998). Obliterative central bronchitis due to mineral dust in patients with pneumoconiosis. Archives Pathol. Lab. Med. 122 (1): 56 - 62.

Kocks D. J. and Scott, D. D. (1990) Ammonia still a health hazard in work place South African Medical Journal 78, 45.

Malmberg, P., Hedenstrom, H. and Sundblad, B. M. (1993) Changes in lung function of granite workers exposed to moderately high silica concentration: A 12 year follow-up. Br. J. Ind. Med. 50 (8): 726 731.

Ng, T. P., Phoon, W. H., Lee, H. S., Ng, Y. L. and Tan, K. T. (1992). An epidemiological survey of respiratory morbidity among granite quarry workers in Singapore: Chronic bronchitis and lung function impairment. Ann Cardiopul. Med. Singapore 21 (3): 312 - 317.

Osim. E. E. and Esin, R. A. (1996). Lung function studies in some Nigerian bank workers. Central Afr. J. Med. 42 (2): 43 46.

Osim, E. E., Musabayane C. T. and Mufunda J. (1998). Lung function of Zimbabawean farm workers exposed to flue curing and stacking of tobacco leaves. South African Medical Journal 88 (9): 1127 - 1131.

Peters, E. J., Esin, R. A., Immananagha, K. K., Siziya, S. and Osim, E. E. (1999). Lung function status of some Nigerian men and women chronically exposed to fish drying using burning firewood: Central Afr. J. Med. 45 (5): 119 - 124.

Raphael, J. C., Elkharat, D., Jars-Guincestre, M. C., chastang, C., Charles, V., Vereken, J. B. and Gajdos, P. (1989). Trail of Normobaric and Hyperbaric oxygen for acute carbon monoxide intoxication. Lancet. $414-419$.

Sawa, G. M., Watson, C. P. N. and Terbangge, K. (19981) Delayed encephalopathy following carbon monoxide intoxication. Can. J. Neurol Sci. 8: 77 - 79 .

Wang, X., Yano, E., Nonaka, L., Wang, M. and Wang, Z. (1997) Respiratory impairment due to dust exposure: A comparative study among workers exposed to silica asbestors and coalmine dust. Am. J. Ind. Med. 31 (5): 495 - 502.

West, J. B. (1979). Respiratory Physiology The Essentials. Williams and Willkin, Baltimore, pp 206 - 221.

World Health Organization (1998) Life in the $21^{\text {st }}$ Century: A vision for all. World Health Organization Report. Geneva; pp $90-95$.

Wright J. L., Iron, V., Wiggs, B. and Churg, A. (1988). Cigarette smoking potentiates asbestos -induced air flow abnormalities, Exp. Lung Resp. 14:537- 542.

Received: October 28, 2004

Accepted: December 6,2004 